\title{
Analisys of sea transportation processes with network and simulation modeling
}

\author{
Mariia Vinnikova ${ }^{1,2, *}$ and Anton Semenov ${ }^{1,3}$ \\ ${ }^{1}$ Admiral Makarov State University of Maritime and Inland Shipping, 198035, St. Petersburg, Russia \\ ${ }^{2}$ BF Tanker Ltd., Bolshoy Prospekt of Vasilievsky island, 80, St. Petersburg, Russia \\ ${ }^{3}$ Yanino Logistics Park LLC, Vsevolozhsky District, Yanino-1 village, Trade and logistics zone \\ Yanino-1, No. 1, Leningrad Region, Russian Federation
}

\begin{abstract}
The paper examines a complex of operations in sea transport using methods of network and simulation modeling. The authors consider the process of organizing sea transportation for the tanker fleet. In this case, the whole procedure is divided into four blocks of work. Each of the blocks is investigated separately using the network modeling method. The result of a private study is network models that describe the logic of performing a set of works, as well as the average execution time of all operations. It is proved that the use of simulation modeling for the analysis of the process of organizing and performing sea transportation makes it possible to assess the distribution of the execution time of the entire complex of works, as well as to identify bottleneck. The information obtained can be used for the subsequent analysis of the features of the work performance that reduce the efficiency of operations in the sea transportation process, and the development of possible solutions to improve the procedures under consideration.
\end{abstract}

\section{Introduction}

More and more transport companies are now digitalizing their internal operations, affecting both the administrative and technological aspects of their activities. Digitalization allows simplifying and speeding up the process of exchanging and registering information, as well as increasing control over the execution of operations. As a result, the ability to register the execution time of individual stages of each process performed in the company gives space for analysis and improving the efficiency of its activities [1-4].

At the same time, the development and implementation of information systems is a timeconsuming task, the solution of which is difficult to standardize, since the internal processes of each company have their own individual characteristics. As a result, before implementing new software products, it is necessary to structure the logic and sequence of internal processes of the company, i.e. to formalize processes. Network planning methods can be used for this purpose. The formalized representation of transport processes can be used as a technical task for the software developer, as well as for the analysis of these processes [5-8].

\footnotetext{
* Corresponding author: mara.1990@yandex.ru
} 
Every work in the network schedule requires some kind of execution time. In general, this time is a random variable. The execution time of some operations may show significant deviations from the average costs usually required to perform these procedures. As a rule, this is due to certain systematic errors, the elimination of which will reduce the execution time of these operations. The use of simulation modeling for the study of transport processes allows determining those works that, under the influence of local factors, reduce the efficiency of the procedure as a whole [9]. Once the processes that need to be worked out are identified, it will be possible to purposefully select tools and methods to improve the performance of these operations. Therefore, the study of the internal operations of the company leads not only to the possibility of digitizing the complex of works on transport performed by a person, but also to improve the efficiency of the entire system as a whole.

The purpose of this work is to formalize and analyze the process of sea transportation from the point of view of the ship owner. As mentioned above, the same processes may differ from company to company. In this regard, the process under study is considered with the following limitations:

- the tanker fleet is considered for transportation;

- ports of loading and unloading are located outside the Russian Federation;

- the charterer and the consignee are the same legal entity;

- the counterparties of this transaction are non-residents of the Russian Federation;

- the contract is governed by English law;

- the loading agent and the unloading agent have their own forwarding department, which is appointed by the charterer and the shipper to organize the work;

- brokers do not participate in this transaction;

- the route of the cruise is laid in the sea spaces that do not cause the need for transit through the internal waterways of the Russian Federation.

The presented conditions are the most common for the practice of cargo transportation on tankers. This formalized process can be taken as a basis and adapted for the activities of other transport companies.

\section{Methods and materials}

The beginning of the described transport process is the moment when the ship owner receives a request from the charterer containing a brief commercial offer and requirements for the vessel. The end of the process - the moment of completion of all settlements that have arisen in this transportation.

Sea transportation is a complex operation that involves the interaction of many counterparties. Investigating a process of this level of complexity is a time-consuming task. In this regard, to simplify the analysis procedure, the entire complex of works performed during sea transportation is divided into several blocks, each of which contains logically related operations:

1) charter of a vessel;

2) part of the cruise from the moment the agreed terms of the transaction are transferred to the fleet operation department until the vessel leaves the port of loading;

3) part of the cruise from the moment the vessel leaves the port of loading until the moment the vessel leaves the port of unloading;

4) summing up the financial and legal results of the cruise.

The sequence of execution of these blocks is shown in figure 1 . 


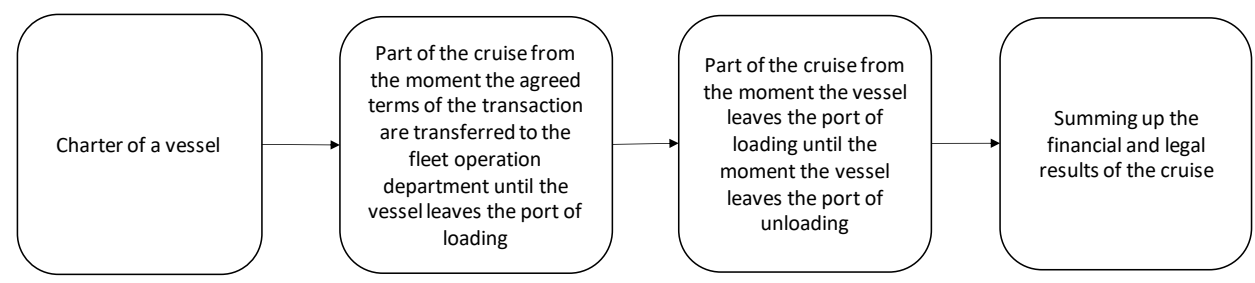

Fig. 1. General scheme of organization of sea transportation.

For each block of operations, a separate matrix of events performed in this block is constructed, on the basis of which a network model of performing operations from this block is then formed [10-12]. As an example, the event matrix for the first block of sea transportation is shown below (table 1) and the corresponding network model (figure 2). Each block is considered in more detail in works [13-14].

Table 1. An example of the event matrix for the first block of sea transportation.

\begin{tabular}{|c|c|c|}
\hline Event description & $\begin{array}{l}\text { Initial work } \\
\text { code "ii" }\end{array}$ & $\begin{array}{l}\text { Code of the } \\
\text { final work "j" }\end{array}$ \\
\hline an offer for transportation from the charterer is received & 1 & 2 \\
\hline $\begin{array}{l}\text { the preliminary freight rate was calculated and a positive } \\
\text { decision was made to start negotiations }\end{array}$ & 2 & 3 \\
\hline $\begin{array}{l}\text { a response offer was sent to the charterer, indicating the } \\
\text { preliminary bids and requests. The start of negotiations on } \\
\text { the details of the charter }\end{array}$ & 3 & $4,5,6$ \\
\hline correspondence and agreement of charter terms & 4 & 15 \\
\hline $\begin{array}{l}\text { sending a request to the shipper to verify the suitability of } \\
\text { the vessel's characteristics for the port of loading }\end{array}$ & 5 & 10 \\
\hline $\begin{array}{c}\text { sending a request to the unloading agent to verify the } \\
\text { suitability of the vessel's characteristics for the unloading } \\
\text { port }\end{array}$ & 6 & 7 \\
\hline $\begin{array}{l}\text { verification with the port of the suitability of the vessel's } \\
\text { characteristics for cargo operations }\end{array}$ & 7 & 8 \\
\hline $\begin{array}{l}\text { receiving confirmation from the port of the suitability of the } \\
\text { vessel's characteristics for cargo operations }\end{array}$ & 8 & 9 \\
\hline sending this confirmation to the charterer -the shipper & 9 & 15 \\
\hline $\begin{array}{l}\text { sending a request to the agent to verify the suitability of the } \\
\text { vessel's characteristics for the port of loading }\end{array}$ & 10 & 11 \\
\hline $\begin{array}{l}\text { sending a letter to the port to verify the suitability of the } \\
\text { vessel's characteristics for cargo operations }\end{array}$ & 11 & 12 \\
\hline $\begin{array}{l}\text { receiving a response from the port on the suitability of the } \\
\text { vessel's characteristics for cargo operations }\end{array}$ & 12 & 13 \\
\hline sending this confirmation to the shipper & 13 & 14 \\
\hline sending the confirmation by the shipper to the charterer & 14 & 15 \\
\hline $\begin{array}{l}\text { obtaining by the charterer a complete set of data on the } \\
\text { suitability of the vessel's characteristics for cargo operations } \\
\text { in the selected ports of loading and unloading }\end{array}$ & 15 & 16 \\
\hline $\begin{array}{l}\text { the charterer confirmed to the ship owner that, based on the } \\
\text { results of the inspection, the vessel is suitable for carrying } \\
\text { out this cruise to the selected ports of loading and unloading }\end{array}$ & 16 & 17 \\
\hline $\begin{array}{l}\text { the results of the transaction are agreed and fixed; the } \\
\text { charterer takes time to make a decision }\end{array}$ & 17 & 18 \\
\hline The deal is fixed & 18 & \\
\hline
\end{tabular}




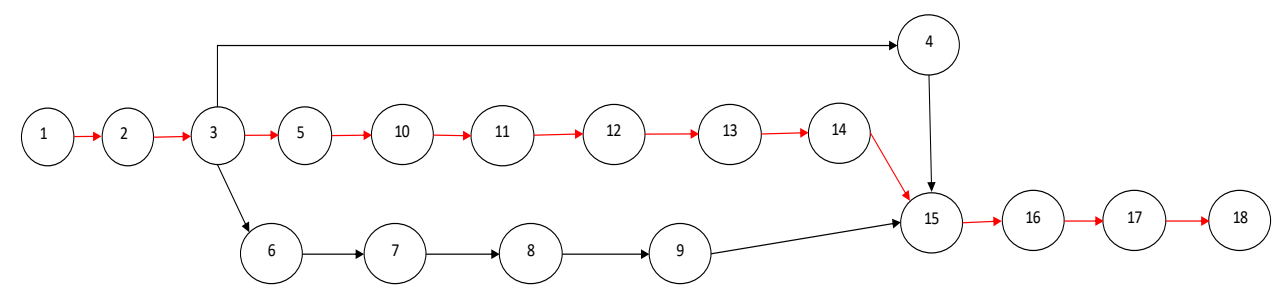

Fig. 2. The network model of block 1 and the critical path of the graph (shown in red).

The arrow in the network schedule conventionally represents the workflow, characterized by time. This process is called "actual work". The arrow also shows the "standby" process, which does not require labor costs, but still takes time. And, finally, just a logical connection of events that does not take time, is called "fictitious work" and is graphically represented by a dotted arrow. An event, as the final result of a completed work or a complex of works, is graphically represented by a circle. Thus, in network schedules, it is the work that is measured, while events are a statement of the fact of the operation performed. Since in the case under consideration, the time of each operation is a random variable, the characteristic of the operation execution time is the probability density.

From the initial event to the final event, several sets of works can be performed simultaneously. These various options for performing work from the initial event to the final one are called complete graph ways. Accordingly, there might be several such complete ways. For example, there are only three possible complete graph ways in figure 2 above. The time of each of them is determined by the sum of the times of individual works:

$$
\mathrm{T}_{\mathrm{ki}}=\sum \mathrm{t}_{\mathrm{j}}
$$

where $T_{k i}$ - duration of the $i$-th way of $k$-th block; $t_{j}$ - duration of $j$-th work.

Among all possible graph ways, the one that takes the maximum amount of time is called the critical way (figure 2). The critical way is the most important value, since it determines the time for which the entire complex of graph operations will be completed. In this case, if all events on the graph are connected by the logic of "And", then the duration of the critical way will be determined as the maximum of the times of all possible ways by the formula:

$$
\mathrm{T}=\max \left(\left\{\mathrm{T}_{\mathrm{i}}\right\}\right)
$$

where $\mathrm{T}$ - time of execution of the entire complex of works; $\left\{\mathrm{T}_{\mathrm{i}}\right\}$ - array of ways durations.

The resulting network schedules will allow estimating the time required to complete the entire complex of works in sea transportation. In this case, the usual mathematical methods for determining the execution time of the entire procedure can not be used: for operations with random variables, the Monte Carlo method must be used [15-16]. An example of the results of modeling - the time distribution of the first block of works and the distribution of critical ways - is shown in figures 3 and 4 . 


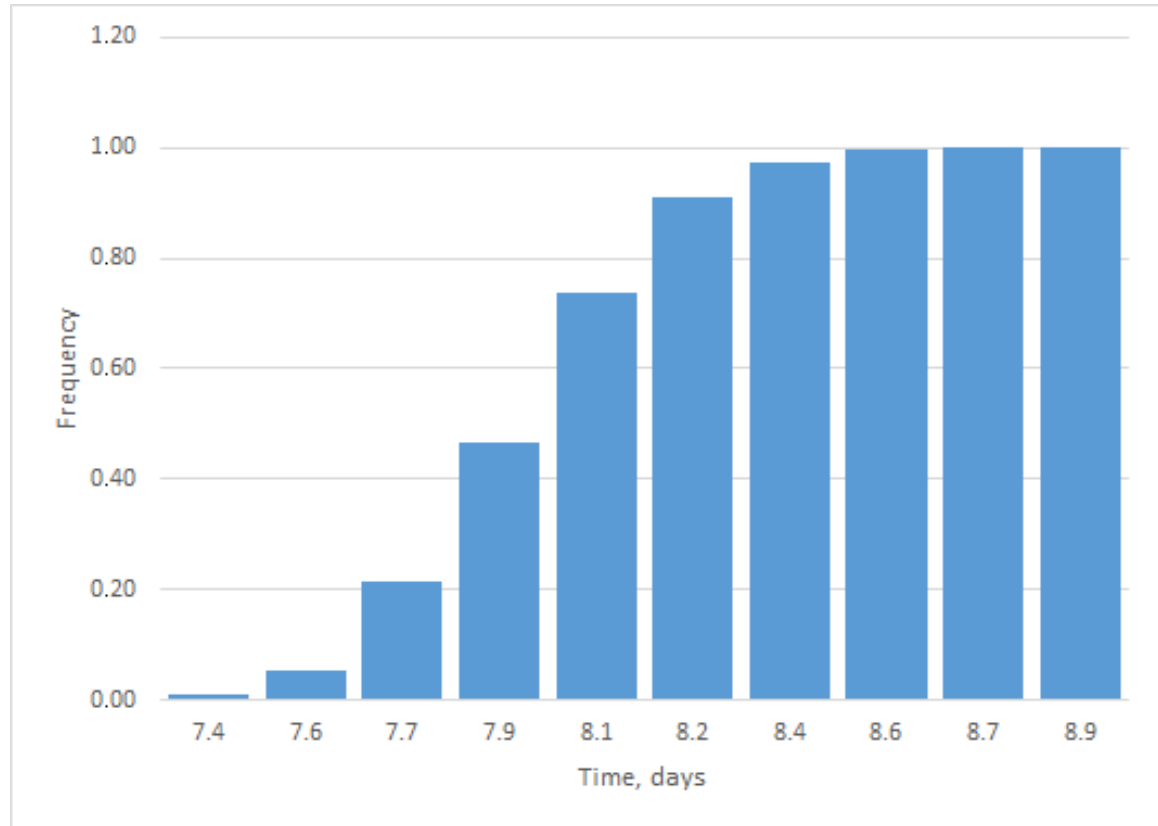

Fig. 3. Distribution of the execution time of the works of block 1.

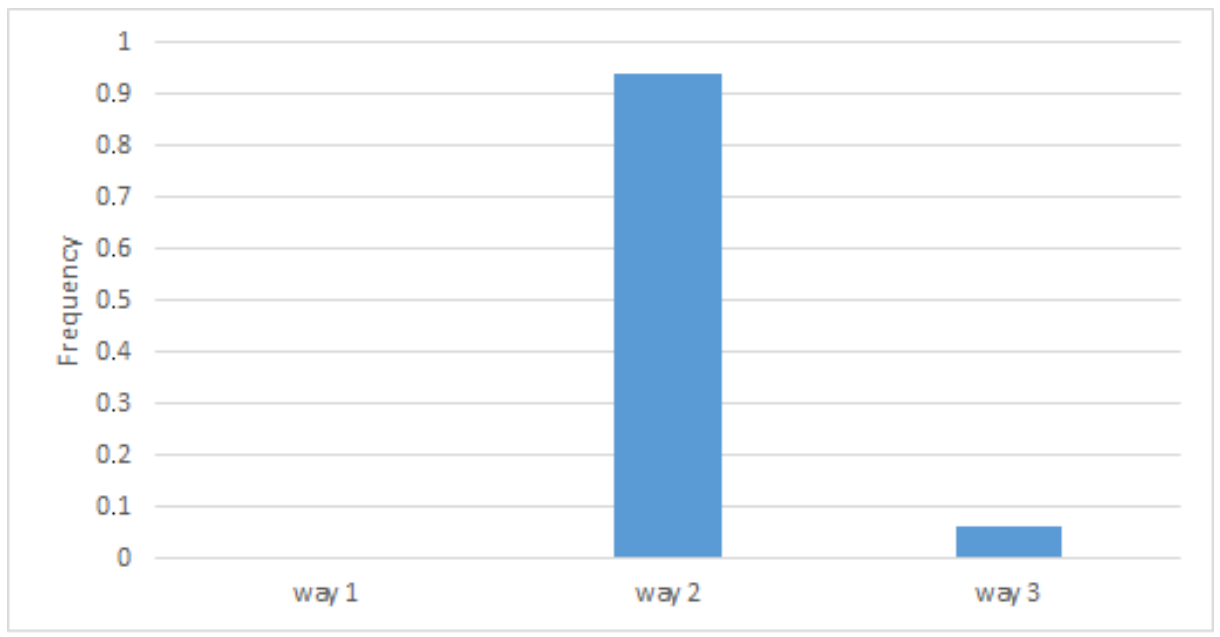

Fig. 4. Distribution of critical paths for block 1 .

The obtained distributions of the time of works completion for each of the blocks allow estimating the time of completion of the entire complex of works in sea transportation. The execution time of all four blocks is determined as follows:

$$
\mathrm{T}_{\text {total }}=\mathrm{T}_{1}+\mathrm{T}_{2}+\mathrm{T}_{3}+\mathrm{T}_{4}
$$

where $T_{j}$ - time of execution of the $j$-th complex of works.

To estimate the time distribution of the entire complex of works, many experiments are conducted, in each of which the time of works execution from a separate block is generated according to the distributions obtained at the previous stages (figure 5). 


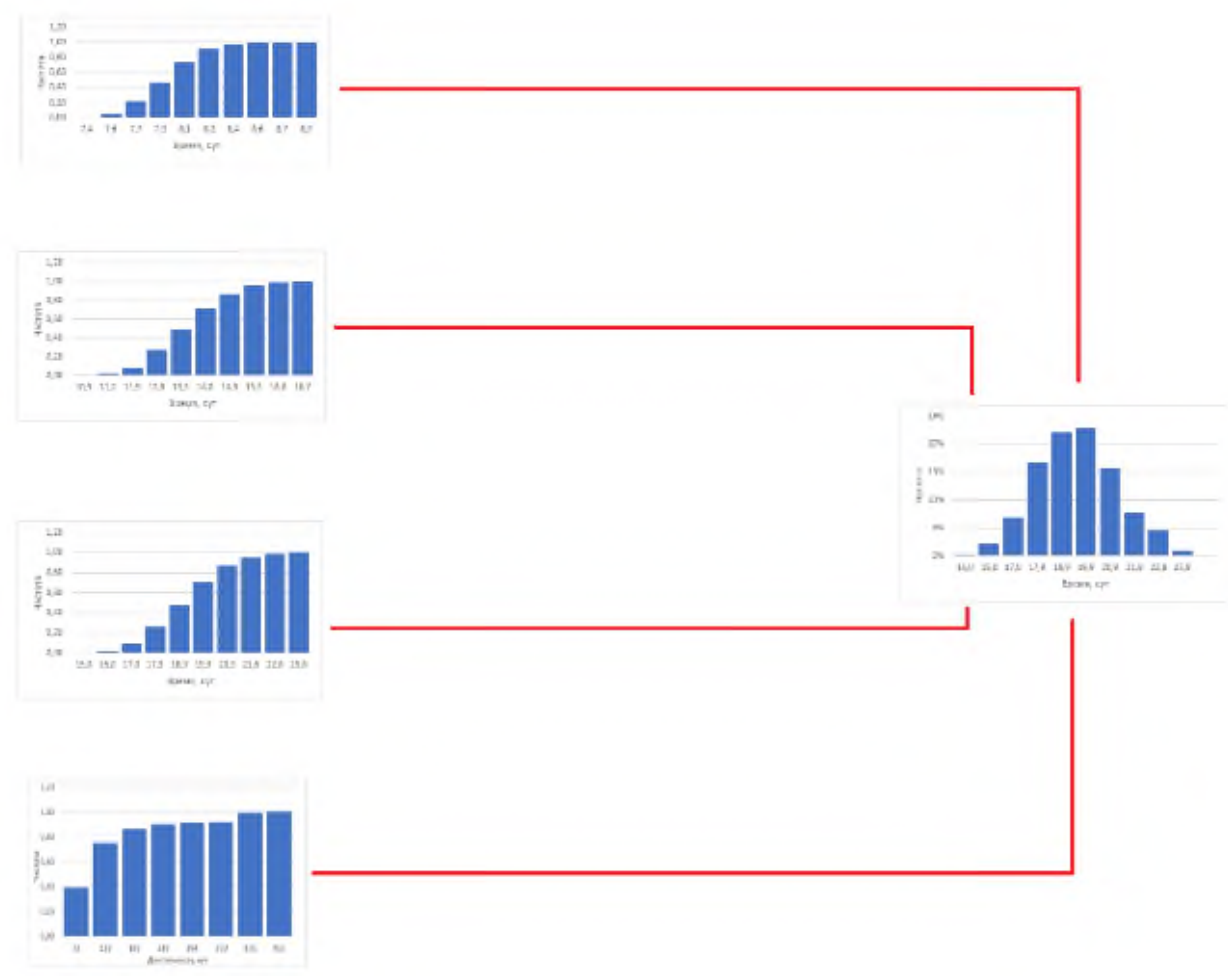

Fig. 5. Estimation of the time distribution of the complex of works execution on the basis of the obtained distributions for four blocks.

The time distribution of the entire complex of works execution and its integral function are shown in figures 6 and 7, respectively.

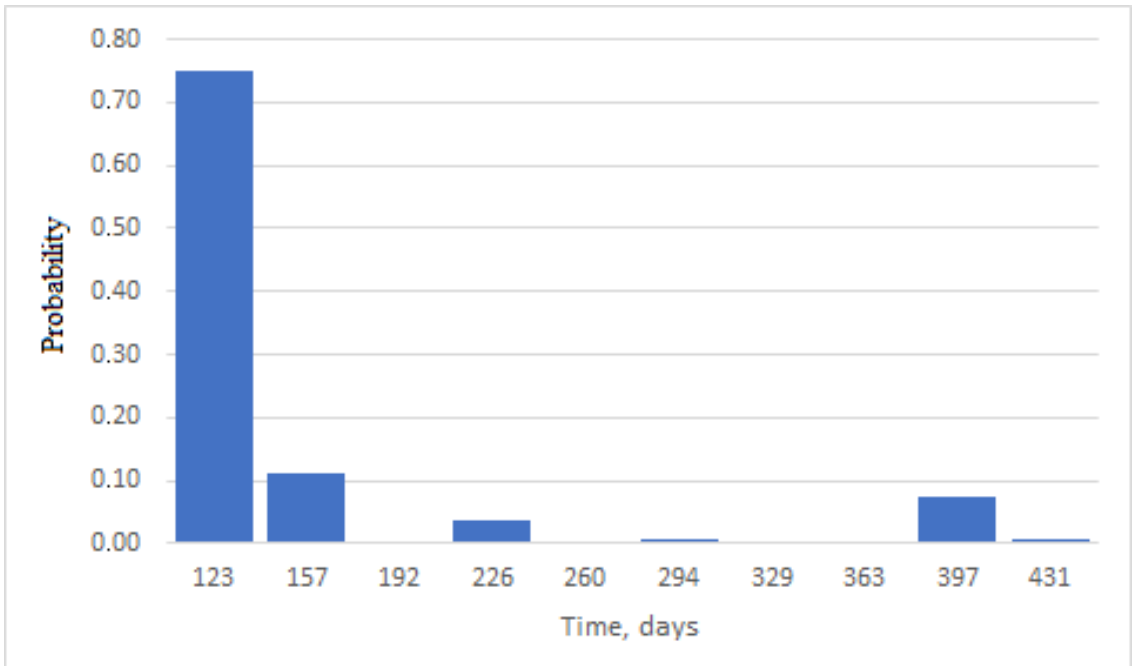

Fig. 6. Time distribution of the entire complex of works execution. 


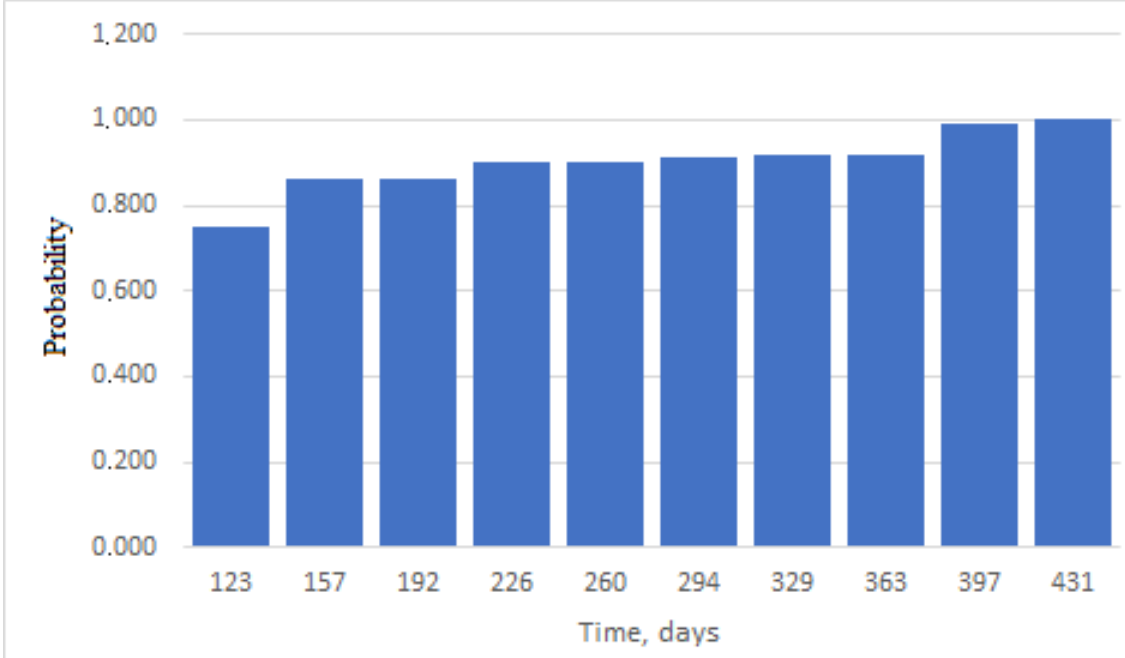

Fig. 7. Integral function of the time of the entire complex of works execution.

\section{Discussion}

To prove the adequacy of the simulation models of individual blocks, the modeling results by Monte Carlo method are compared with the results of network modeling. The average time to complete a complex of works obtained by different methods is shown in table 2 .

Table 2. Results of network modeling and simulation modeling.

\begin{tabular}{|c|c|c|}
\hline BLOCK number & Network modeling, days & Simulation modeling, days \\
\hline 1 & 9 & 8 \\
\hline 2 & 11.5 & 13.5 \\
\hline 3 & 16 & 19.5 \\
\hline 4 & 68 & 72 \\
\hline
\end{tabular}

The results obtained by the methods of network and simulation modeling are quite close, which proves the adequacy of the simulation models.

The calculation of the time of the entire complex of works execution has shown the execution time of sea transportation from the position of a ship owning company from the beginning of chartering of the vessel and prior to completion of settlements for cruise is approximately 4 months.

In addition, as a result of the analysis of the works for the second and third blocks, which describe the processes during the passage of the vessel to the port of loading and completion of loading operations and to the port of unloading and completion of unloading vessel's operations, respectively, it turned out that in the process of performing these complexes of works, the most time-consuming procedures are:

- The process of approval of disbursement accounts at the ports of loading / unloading;

- The process of forming a package of documents by the crew for registration of the vessel's approach to the port of loading / unloading.

The speed of operations in the fourth block - summing up the financial and legal results of the cruise - has the strongest impact on the increase in the time required to complete the entire complex of procedures. This is due to the fact that in some cases, the procedure for 
summing up the legal results of the cruise can be greatly delayed due to disagreements between the ship owner and the charterer.

The network schedules and time distributions of individual works execution, obtained in the course of the study can be used in information systems to build Gantt charts, which set specific dates and time when each individual work should be completed. This data is displayed in the information system as a specific task that the employee must complete up to a given point in time. This approach significantly increases the control over the activities of employees, and also allows analyzing how the time for performing the entire complex of works will change if one of the operations is performed later.

In addition, as mentioned above, the execution time of individual operations is a random variable. In this case, it is difficult to establish a single norm for each work execution. Instead, it is necessary to build several variants of Gantt charts, in which the time of the complex of works execution is one of the quantiles of the distribution of a random variable. From this point of view, instead of a single date and time of work execution, the information system can specify the range within which this operation should be performed.

\section{Conclusion}

The study of the process of sea transportation allowed determining that:

1. the study of operations using the methods of network and simulation modeling allows formalizing and analyzing the processes of the transport company operation;

2. the result of the analysis is the distribution of the time of the complex of works execution;

3. the time to complete the entire complex of works from the moment of the beginning of the chartering of the vessel to the full completion of mutual settlements for the cruise is on average 4 months;

4. with a probability of $17 \%$, it may take from five months to a year to complete the entire procedure;

5. the probability that the process of closing mutual settlements on the cruise will be greatly delayed and will take more than a year is approximately $8 \%$.

\section{References}

1. C.A. Vural et al., Research in Transportation Business \& Management 37, 100525 (2020) DOI: 10.1016/j.rtbm.2020.100525

2. A. Alop, International Journal on Marine Navigation and Safety of Sea Transportation 13(3), 521-528 (2019) doi:10.12716/1001.13.03.05

3. P.L. Sanchez-Gonzalez et al., Sensors 19(4), 926 (2019) DOI: 10.3390/s19040926

4. M.M. Baldauf, M. Kitada, R. Mehdi, D. Dalaklis, INTED2018 Proceedings, 9525-9530 (2018) DOI: 10.21125/inted.2018.2374

5. A. Kozminski, J. Dariusz, The New Principles of Management (Peter Lang D., Bern, Switzerland, 2013) DOI: 10.3726/978-3-653-02998-7

6. M. Hammer, Handbook on Business Process Management 1. International Handbooks on Information Systems (Springer, Berlin, Heidelberg, 2015) DOI: 10.1007/978-3-64245100-3_1

7. M. Rosemann, J. vom Brocke, Handbook on Business Process Management 1. International Handbooks on Information Systems (Springer, Berlin, Heidelberg, 2015) DOI: 10.1007/978-3-642-45100-3_5 
8. J. Mendling et al., ACM Transactions on Management Information Systems (TMIS) 9(1), 1-16 (2018) DOI: 10.1145/3183367

9. A. Elentably, International Journal on Marine Navigation and Safety of Sea Transportation 10(2), 331-337 (2016) DOI: 10.12716/1001.10.02.16

10. J. Burbank, W. Kasch, J. Ward, Institute of Electrical and Electronics Engineers, 203 (2011) DOI: 10.1002/9781118063651

11. M. Guizani, A. Rayes, B. Khan, A. Al-Fuqaha, Network Modeling and Simulation: A Practical Perspective (John Wiley \& Sons, Ltd., 2010) DOI: 10.1002/9780470515211

12. A.L. Kuznetsov, Bulletin of the Admiral Makarov State University of Maritime and Inland Shipping 2(60), 230-238 (2020) DOI: 10.21821/2309-5180-2020-12-2-230-238

13. M.D. Diakonova, A.D. Semenov, Bulletin of the Admiral Makarov State University of Maritime and Inland Shipping 3(61), 504-514 (2020) DOI: 10.21821/2309-5180-202012-3-504-514

14. M.D. Diakonova, A.D. Semenov, Bulletin of the Admiral Makarov State University of Maritime and Inland Shipping 5(63), 884-893 (2020) DOI: 10.21821/2309-5180-202012-5-884-893

15. H. Barreto, F. Howland, Cambridge University Press, 215-237 (2005) DOI: 10.1017/CBO9780511809231.011

16. A.L. Kuznetsov, A.V. Kirichenko, A.D. Semenov, Bulletin of the Admiral Makarov State University of Maritime and Inland Shipping 3(61), 526-536 (2020) DOI: 10.21821/2309-5180-2020-12-3-526-536 